\title{
A case of transient hyperphosphatasemia presenting with mild degree of bow legs
}

\author{
Kankananarachchi I ${ }^{1}$, Athukorala $\mathrm{M}^{2}$, Atapattu $\mathrm{N}^{2}$ \\ ${ }^{1}$ Faculty of Medicine, University of Ruhuna, ${ }^{2}$ Lady Ridgeway Hospital
}

\section{Abstract}

Introduction: Transient Hyperphosphatasia (TH) is a benign condition in which serum Alkaline Phosphatase is elevated without any underlying pathology. This is mainly seen in children compared to adults and it is usually an incidental finding. The hallmark of the condition is that normalization of ALP level will with time. However, not knowing the entity would lead to unnecessary investigations and referrals. Here we report a child with $\mathrm{TH}$ who presents with a mild degree of bow legs.

Case report: A 1year and 8 months old boy was brought by his mother with a concern of bow legs. He was the first child born to non-consanguineous healthy parents following normal antenatal and perinatal periods. His birth weight was $3.5 \mathrm{~kg}$ and he was growing in his birth centile. He had age-appropriate development and parents had been having a concern about bow legs after he started walking. He is getting an average Sri Lankan diet with animal food and he gets adequate sun exposure as well. There was no history to suggest the liver of renal diseases.

On examination, he had a mild degree of bow legs without any features to suggest rickets. His cardiovascular, respiratory, abdominal, and neurology exams were normal.

His bone profile showed a high value of ALP (3782 U/L) with normal calcium, phosphate, and vitamin D levels. Due to high ALP levels, he underwent liver and renal functions and that was within the normal range.

The diagnosis was made as TH and he was followed up monthly with ALP values. He had a downward trend of ALP levels and in 3 months the ALP value dropped to (580 U/L). Parents were reassured about the condition and the diagnosis was confirmed as TH.

Conclusion: It is important to rule out, bone, kidney, or a liver pathology if a child has markedly elevated ALP levels. However, it is important to recognize this entity to avoid unnecessary procedures and concerns.

Keywords: Hyperphosphatasemia, Transient, children, bow legs

Correspondence email: imalke462@gmail.com

D https:/ / orcid.org/0000-0002-9351-2966

This is an open-access article distributed under the terms of the Creative Commons Attribution License, which permits unrestricted use, distribution, and reproduction in any medium, provided the original author and source are credited (CC BY 4.0) 
Introduction

Transient hyperphosphatasemia (TH) is a benign condition in which serum Alkaline Phosphatase is elevated without any underlying pathology. This is mainly seen in children compared to adults and it is usually an incidental finding. The hallmark of the condition is that normalization of Alkaline Phosphatase (ALP) level will with time. However, not knowing the entity would lead to unnecessary investigations and referrals. Here we report a child with $\mathrm{TH}$ who presents with a mild degree of bow legs.

\section{Case report}

A 1year and 8 months old boy was brought by his mother with a concern of bow legs. He was the first child born to nonconsanguineous healthy parents following normal antenatal and perinatal periods. His birth weight was $3.5 \mathrm{~kg}$ and he was growing in his birth centile. He had age-appropriate development and parents had been having a concern about bow legs after he started walking. He is getting an average Sri Lankan diet with animal food and he gets adequate sun exposure as well. There was no history to suggest the liver or renal diseases.

On examination, he had a mild degree of bow legs without any features to suggest rickets. His cardiovascular, respiratory, abdominal, and neurology exams were normal.

His bone profile showed a high value of ALP (3782 U/L) with normal calcium, phosphate, and vitamin D levels. Due to high ALP levels, he underwent liver and renal functions and that was within the normal range. (Table 1).

The provisional diagnosis was made as $\mathrm{TH}$ and he was followed up monthly with ALP values. He had a downward trend of ALP levels and in 3 months the ALP value dropped to $(580 \mathrm{U} / \mathrm{L})$. Parents were reassured about the condition and the diagnosis was confirmed as TH. (Table 2)

\section{Table 1: Investigation summary}

\begin{tabular}{lll}
\hline Investigation & Value & Reference range \\
\hline ALP & 3782 & $(175-476 \mathrm{u} / \mathrm{l})$ \\
Corrected calcium & $2.34 \mathrm{mmol} / \mathrm{L}$ & $(2.25-2.75 \mathrm{mmol} / \mathrm{l})$ \\
Serum Phosphate & $1.79 \mathrm{mmol} / \mathrm{L}$ & $(1.45-2.16 \mathrm{nmol} / \mathrm{l})$ \\
Vitamin D & $72.6 \mathrm{nmol} / \mathrm{L}$ & $(23-113 \mathrm{nmol} / \mathrm{l})$ \\
Alanine Transaminase (ALT) & $26 \mathrm{U} / \mathrm{L}$ & $(10-31 \mathrm{u} / \mathrm{l})$ \\
Serum albumin & $44 \mathrm{~g} / \mathrm{L}$ & $(34-54 \mathrm{~g} / \mathrm{L})$ \\
Serum creatinine & $16 \mathrm{umol} / \mathrm{L}$ & $(27-62 \mathrm{umol} / \mathrm{l})$ \\
\hline
\end{tabular}




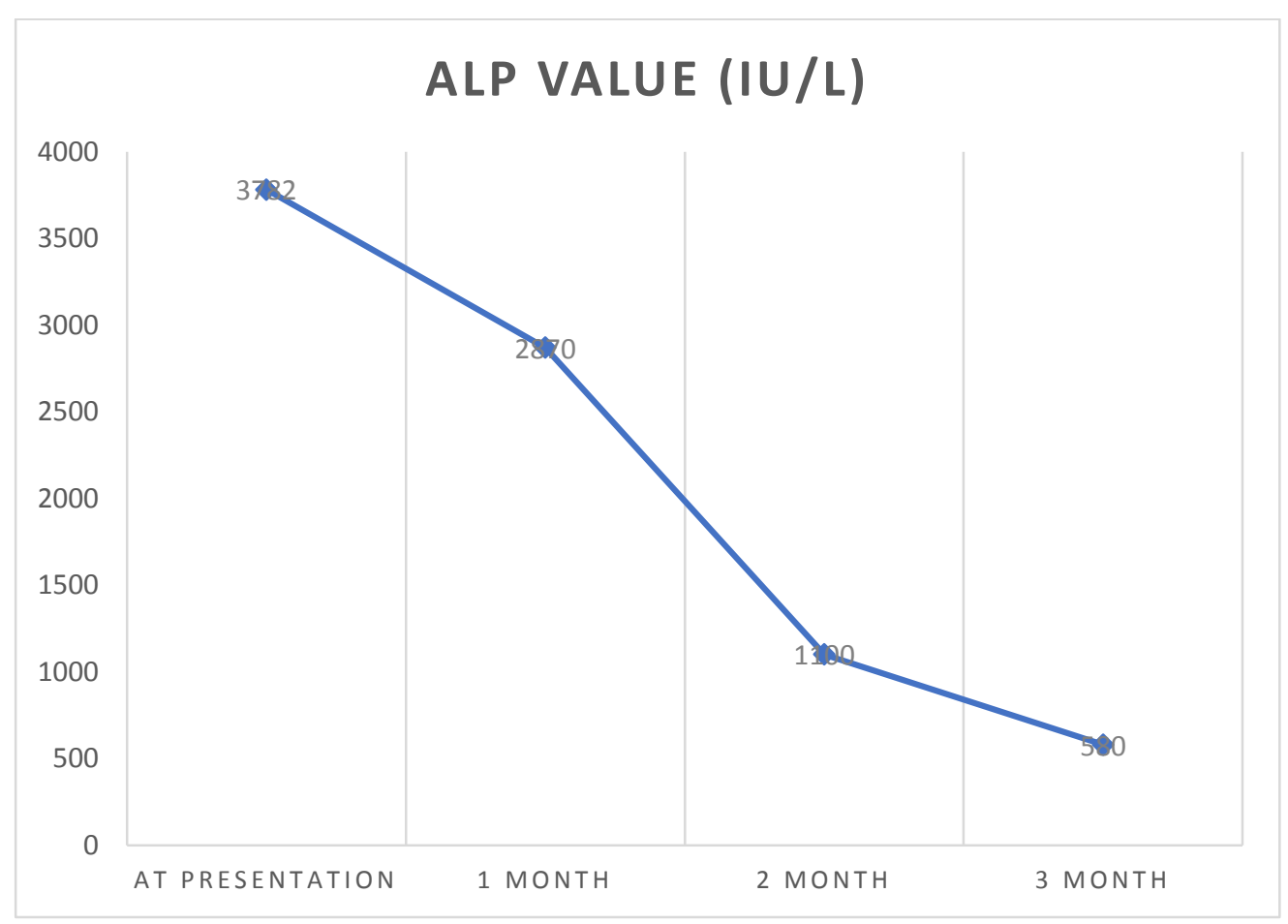

\section{Discussion}

TH in infancy and childhood is defined as an isolated elevation of ALP in a child less than 5 years, without any clinical, laboratory, or radiological finding of a systemic illness that presents with a similar biochemical profile ${ }^{(1)}$. Kidney, Liver, Bone, Intestine, and white blood cells are the main sources of serum ALP. The normal value of ALP varies with the age and it is usually higher in childhood compared to adults. Moreover, ALP levels can go up physiologically, when there is a high osteoblastic activity in the body such as the first 6 months of life and puberty ${ }^{(2)}$.

In TH, ALP levels can be even 20 times higher than the upper limits of paediatric reference ranges and it usually resolves by 46 months $^{(3)}$. Though this is a known phenomenon for a long time, the exact mechanism is not known yet. In some centers, children have been followed up to 4 years but none of them had any long-term complications $^{(4)}$.

In this child, the ALP value normalizes in 34 months without any interventions. The exact diagnosis of the condition can be made retrospectively once the ALP level has come down to baseline ${ }^{(1)}$. However, if it is not behaving in this manner it is important to look into other causes of hyperphosphatasemia such as rickets, hepatic dysfunctions and chronic kidney disease. Bow legs is very common under 2 years of age and it is a normal physiological phenomenon in most occasions ${ }^{(5)}$.

In this case, bow legs are highly likely to be due to physiological rather than any link with the $\mathrm{TH}$. 


\section{Conclusion}

It is important to rule out, bone, kidney, or a liver pathology if a child has markedly elevated ALP levels. However, it is important to recognize this entity to avoid unnecessary procedures and concerns.

\section{Reference}

1. Wolf PL. The significance of transient hyperphosphatasemia of infancy and childhood to the clinician and clinical pathologist. Arch. Pathol. Lab. Med. 1995;119 (9):774-5.

2. Turan S, Topcu B, Gökçe I, Güran T, Atay Z, Omar A, Akçay T, Bereket A. Serum alkaline phosphatase levels in healthy children and evaluation of alkaline phosphatasez-scores in different types of rickets. Journal of clinical research in pediatric endocrinology. 2011 Mar;3(1):7.

3. Behúlová $\mathrm{D}$, Bzdúch $\mathrm{V}$, Holesova $\mathrm{D}$, Vasilenková A, Ponec J. Transient hyperphosphatasemia of infancy and childhood: study of 194 cases. Clinical chemistry. 2000 Nov 1;46(11):1868-9.

4. Posen S, Lee C, Vines R, Kilham H, Latham S, Keefe JF. Transient hyperphosphatasemia of infancy--an insufficiently recognized syndrome. Clinical chemistry. 1977 Feb 1;23(2):292-4.

5. Ganavi R. Bow legs and knock knees: is it physiological or pathological. Int J Contemp Pediatrics. 2016 Apr;3:687-91. 